- Current research on residency innovation is available through Family Medicine's recent dedicated issue on residency redesign.

- TeachingPhysician.org connects residency programs with community preceptors. The web resource streamlines training with videos, tips, answers to frequently asked questions, and links to in-depth information on precepting.

STFM is strengthening its offerings to help residencies successfully meet today's challenges as they train tomorrow's family physicians. We invite residency faculty to explore the wealth of STFM offerings and offer feedback on challenges that are not yet being met. We strive to be the go-to resource for all family medicine educators.

Traci Nolte, CAE, Director, Publications and Community Mary Theobald, MBA, Vice President Communications and Programs

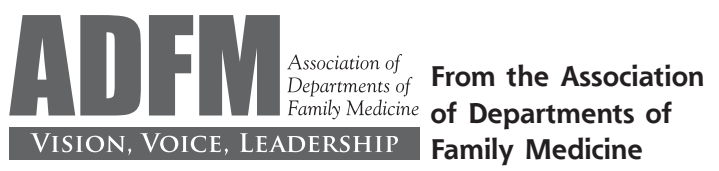

Ann Fam Med 2012;10:370-371. doi:10.1370/afm.1424.

\section{ADFM'S FELLOWSHIP PROGRAM}

Three years ago ADFM reported the need to develop an effective pipeline for family medicine department chairs. ${ }^{1}$ Prompting this report were results from our 2008 survey, in which nearly one-half (47\%) of chairs reported a possible or probable change in departmental leadership in the next 3 years. One year later, our 2009 data indicated a more imminent turnover in chair positions with $52 \%$ chairs reporting plans to leave their positions within 2 to 5 years and $20 \%$ planning to leave within 2 years or less. Turnover in chair positions is not a new phenomenon. Since 2005, our data show that 10 to 15 new chairs (interim and permanent) have come into ADFM each year, and the trend has accelerated this past year as 19 new family medicine chairs joined ADFM between February 2011 and February 2012.

In response to the chair pipeline concern raised in 2008, ADFM launched the ADFM fellowship program. The ADFM fellowship is a 1-year program designed for family physicians who aspire to become a chair in the near future. Since 200913 fellows have completed the ADFM fellowship, 6 of whom (46\%) have assumed chair positions. There are 3 additional fellows in our current 2012-2013 class, and we will be recruiting for a new class of fellows in the fall of 2012 for the 2013-
2014 fellowship class. Below is a description of the program and application process.

Curriculum components of the ADFM fellowship include:

- Attendance at 2 consecutive ADFM Annual Winter Meetings. Annual ADFM Winter meetings are in February and run from the opening reception on Wednesday evening through Saturday at noon. The 2013 winter meeting is scheduled for February 20-23, 2013 in New Orleans, Louisiana. The 2014 winter meeting has not been scheduled yet but the timeframe will be similar.

- Attendance at 1 ADFM Fall Meeting in conjunction with the AAMC annual meeting. In 2013, this meeting will be in early November in Philadelphia, Pennsylvania.

- Assignment to a faculty advisor who will work oneon-one with each fellow to help guide them through the fellowship.

- Participation on the ADFM Chairs' list-serve for the duration of the fellowship. List-serve participation allows fellows to learn about potential chair opportunities and about the many issues facing chairs in their everyday jobs.

- Meetings with other fellows and assigned advisors (as scheduled) during the ADFM Annual Winter Meeting to review together all fellows' learning needs (including but not limited to the CV review) and educational plans for the year

- Fellowship projects. In consultation with her/his department chair, the fellow will select a project aimed at increasing the fellow's skills in an area of interest that also benefits the department.

A fellowship application must include:

1. Current curriculum vitae

2. Title of your fellowship project

3. Letter from the chair of your department supporting your aspirations of becoming a department chair and including a statement of: (1) willingness to support the cost of your participation in the fellowship; (2) support of the fellow's year-long participation on the ADFM List-serve; and (3) support of your fellowship project. If you are not from an ADFM member department, a letter from a current ADFM member chair is required.

4. Personal statement regarding aspirations to become a chair (suggested length is 1 to 2 pages). In the personal statement provide an anecdote or describe an event that illustrates your ability to successfully lead a department of family medicine.

5. If you already have a mentor who is a chair of a family medicine department (other than your own department chair) and would like to have that person continue to mentor you in the ADFM fellowship, 
please provide the name of that mentor.The cost of the program is registration for and travel to the 2 ADFM winter meetings and travel to the ADFM fall meeting held in conjunction with the annual meeting of the Association of American Medical Colleges.

Applications will be reviewed by the ADFM executive committee and the ADFM fellowship co-directors. Applicants are notified by late November regarding acceptance into the 2013-2014 ADFM fellowship program. Criteria which are considered in reviewing applications include:

- Complete application packet

- Associate Professor or higher rank

- Involvement in each mission: education, clinical, research/scholarship (and administration)

- Evidence of being prepared for leadership role within dept/institution and outside institution

- MD, DO, or PhD with clinical practice in family medicine

If you have any questions, please do not hesitate to contact either of us or Ardis Davis, MSW, Executive Director, ADFM (ardisd7283@aol.com; 425-423-0922). Macaran Baird, MD, Director, ADFM Fellowship Jobn Hickner, MD, PbD, Co-Director, ADFM Fellowship

\section{References}

1. Newton W, Borkan J, et al: A call for new leaders: building a pipeline for the future of family medicine. Ann Fam Med.2009;7(2):187-188.

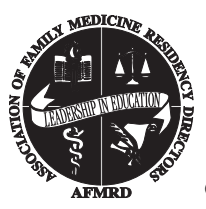

From the Association of Family Medicine Residency Directors

Ann Fam Med 2012;10:371-372. doi:10.1370/afm.1425.

\section{THE NRMP: ALL-IN...AND TESTING THE SOAPY WATERS?}

By many accounts this was a banner year for family medicine in the Match. At 2,740 offered positions, we witnessed a 7-year high. Not since 2000 (when 2,603 positions were filled) have we seen this number of matched applicants into family medicine. After being flat at $91 \%$ from 2008 to 2010 , the fill rate for family medicine programs through the match bumped to $94 \%$ in 2011 and 95\% this year. ${ }^{1}$ These numbers certainly are a cause for some optimism.

Behind these promising numbers, however, lurk some stark realities that point to a looming crisis. The positive upticks noted above do not reflect a significant change in the attitudes of US medical school gradu- ates toward primary care. The increases are largely due to: (1) an increase in the number of medical students graduating, particularly from osteopathic institutions, and (2) a slight increase in the number of family medicine residency positions offered in the Match. Most believe these slots do not represent new positions but are existing ones moved into the Match in anticipation of the All-In policy to be instituted in 2013.

This year the National Resident Mapping Program (NRMP) instituted the Supplemental Offer and Acceptance Program (SOAP). So, did the SOAP program actually help family medicine by allowing unmatched medical students to reexamine or reexplore their specialty choice? Of the 130 family medicine slots available, almost all were filled during the SOAP process. Though the process was successful in filling most of the slots, there were a number of logistical problems. First, United States Medical Licensing Exam (USMLE) scores for applicants were not available on day 1 . Secondly, many of the filters one typically uses in the Electronic Residency Application Service (ERAS) were difficult or impossible to implement. Considering that many programs actually received more applications through SOAP than through the general Match, the lack of filters proved frustrating and very troubling. Lastly, the actual SOAP process can be problematic. For example, if a program has 1 slot available and 4 outstanding candidates, only 1 offer for the position can be made at a time making the need to know that candidate's interest in your program critical. If the candidate is not interested, another offer cannot be made for 2 hours, at which time many of your initial candidates will be gone. Currently the NRMP is seeking active feedback on the SOAP process. For those who participated in the process, your feedback is vital in improving the supplementary Match. Submit this feedback to nrmp@aamc.org.

Next year the NRMP will institute the All-In policy. Therefore, a program will have to offer all of its PGY-1 positions through the Match. In 2008, 3.2\% of all family medicine residency slots were filled outside the Match with only 3 programs not participating in the Match. Up to one-third of all programs offered at least 1 position outside the Match. ${ }^{2}$ The change will affect a large number of programs but its exact impact on the specialty is unknown. The actual guidelines for implementing this policy will be discussed and distributed this summer.

As citizens, we need to be concerned. The US medical education system is not producing a sufficient primary care workforce. As our population ages, more and more medical students are choosing specialties with less and less patient contact. Without significant change, a health care crisis of epic proportions can- 